\title{
The assessment of the optimal time window for prediction of seismic hazard for longwall coal mining: the case study
}

\author{
Piotr Małkowski ${ }^{1}$ [ $\cdot$ Zbigniew Niedbalski $^{1}$ (D) $\cdot$ Wojciech Sojka ${ }^{2}$
}

Received: 1 September 2020 / Accepted: 21 January 2021 / Published online: 7 February 2021

(c) The Author(s) 2021

\begin{abstract}
The dynamic nature of rock mass damage during mining activity generates seismic events. This article shows, how the time window for the database influences on the actual status of seismic hazard for the longwall mining area in one of Polish coal mines using Gutenberg-Richter law. A time window of 10-90 days was assumed with similar or shorter prediction times forecast on its basis. Additionally, for each seismic database the hazard prediction accuracy was determined. The analysis shows that the 10- and 20-day base periods are too short for prediction purposes. The higher-energy seismic events sometimes do not occur within such a short period of time, preventing regression analysis and parameter $b$ determination. The best time window for the seismic hazard prognosis in given geological and mining conditions seems to be 30-50 days. The shorter periods cause the underestimation of the seismic hazard prognosis. Low range of tremor energies and the relatively low number of seismic events with high energy cause the low probability of prediction of the seismic mining events (10-40\%) of the energy of min. $10^{6} \mathrm{~J}$, even for longer day base periods. The accuracy of hazard prediction, obtained from each seismic database period, was determined, using the developed coefficient of hazard autoregression $C_{N}$. The analysis of the Gutenberg-Richter distribution should serve as complementary tool of seismic hazard prediction only.
\end{abstract}

Keywords Seismic hazard in coal mining · Time window for seismic hazard prediction · Gutenberg-Richter distribution · Seismic hazard during longwall mining $\cdot$ Seismic activity during the extraction of a coal seam

\section{Introduction}

Driving of roadways and mining exploitation cause a change of stress magnitude and distribution in the rock mass. The dynamic nature of rock mass damage generates seismic events. Specifying the coordinates of seismic foci and providing the calculated seismic energy of the recorded events are the fundamental data in the procedures of rockburst hazard assessment using seismological methods.

Numerous observations from mines in South Africa (Kijko and Funk 1994; Van Aswegen 2001; Mendecki and Lötter 2011; Wesseloo 2014), England (Bishop et al. 1993),

Communicated by Michal Malinowski (CO-EDITOR-INCHIEF)/Zenon Pilecki (Guest Editor).

Piotr Małkowski

malkgeom@agh.edu.pl

1 Faculty of Mining and Geoengineering, AGH University of Science and Technology, Krakow, Poland

2 JSW Innovation, Katowice, Poland
China (Lu et al. 2015), Poland (Lasocki and Orlecka-Sikora 2008; Lasocki 2008; Gołda and Kornowski 2011) showed that mining-induced seismic events can be described, in a number of aspects, using the same rules as those applied to natural earthquakes. The distinctive features of mining tremors, in contrast to earthquakes, are: ground vibrations frequencies, smaller areas of impact on the environment, and shallow location of hypocentres that correspond to the depth of mining.

Therefore, the Gutenberg-Richter (Gutenberg and Richter 1954) equation used in mining practice is as follows:

$\log N(E)=a-b \cdot \log E$

where $E$ - seismic energy, $N(\mathrm{E})$ - the number of events with a given energy $E, a, b-$ constant parameters of the Gutenberg-Richter distribution.

The assessment and prediction of seismic hazard via the Gutenberg-Richter distribution uses parameters derived from a set of data from seismic events that took place in the hazard area. A seismic hazard prediction based on the 
Gutenberg-Richter distribution is simple and has relatively low requirements as to the database.

However, the simplicity of the Gutenberg-Richter distribution is linked with the uncertainty of assessments and predictions, and it is suggested that the probability of the predictions should be also provided (Kornowski and Kurzeja 2012; Kołodziejczyk et al. 2013).

This article shows, how the database period used in Gutenberg-Richter distribution influences the level of seismic hazard of the longwall mining area. For the study, periods of 10-90 days were assumed.

Additionally, the accuracy of hazard prediction, obtained from each seismic database period, was determined, using the developed coefficient of hazard autoregression $C_{N}$.

The subject of the analysis was an area of two longwall excavations within the field S of the "Murcki-Staszic" hard coal mine. This mine is located in the centre of Upper Silesian Coal Basin in Poland.

\section{Seismic hazard assessment based on the observed seismicity}

Seismic hazard assessment is based on the collected information from a number $N_{T}$ of seismic events, and the latercalculated slope $b$ of the Gutenberg-Richter distribution. Even though the distribution of mining seismic events cannot be accurately approximated with the Gutenberg-Richter model (Lasocki 2008), this model is used for the general assessment of seismic hazard in Polish coal mines.

The primary prediction is the expected number of seismic events $N^{*}{ }_{\Delta t}$ of a given energy that will occur in a specific time interval $\Delta T$. The defined proportion (2) should be fulfilled:

$\frac{N_{\Delta t}^{*}}{N_{T}}=\frac{\Delta t}{T}$

where $T$-observation period (days), $N_{T}$-number of tremors within the observation period.

In accordance with the Gutenberg-Richter distribution, it is assumed that the distribution of exceedances of energy $E$ is expressed by formula (1), however, for a given number of tremors in the database $N_{T}$ (Kurzeja and Kornowski 2013; Kołodziejczyk et al. 2013):

$a=\log N_{T}$

and

$E=\frac{E^{*}}{E_{p}}$ where $E^{*}$ - energy of the predicted exceedances, $E_{p}$-minimum observed energy.

Hence, by applying Eqs. (3) and (4) to Eq. (1) the following relationship is obtained:

$N_{\Delta t}^{*}=\left(\frac{\Delta t}{T}\right) \cdot N_{T}=\left(\frac{\Delta t}{T}\right) \cdot 10^{\log N_{T}}=\left(\frac{\Delta t}{T}\right) \cdot 10^{\log N_{T}-b \cdot \log \left(\frac{E^{*}}{E_{p}}\right)}$

Dependency (5) shows that from the number $N_{T}$ of tremors recorded in a given area, and using the slope of the Gutenberg-Richter distribution $b$, it is possible to estimate the hazard, specified as the possible number of tremors of an energy $E^{*}$.

Assuming that sequences of mining-induced seismic events can be approximated using the Poisson statistical model, it is also possible to determine the probability of a seismic event of energy $E>E^{*}$ (Lasocki 2008; Gołda and Kornowski 2011; Kołodziejczyk et al. 2013; Wesseloo 2018). The estimator of seismic hazard $Z_{\Delta t}^{s}$ in the chosen time $\Delta T$ is Eq. (6) (Gibowicz and Kijko 1994; Kornowski and Kurzeja 2012; Kurzeja and Kornowski 2013), in which the number of tremors in a time unit (per day) $N_{T}{ }^{*}$, and parameter $b$ become the random variables of this probability:

$Z_{\Delta t}^{s}=P\left(E>E^{*}\right)_{\Delta t}=1-\exp \left[-N_{T}^{*} \cdot \Delta t \cdot\left(\frac{E^{*}}{E_{p}}\right)^{-b}\right]$

The effectiveness of seismic hazard prediction for the specified prediction time window was checked based on the seismic records during the longwall panel extraction in the chosen mine, and with a help of the developed by the authors coefficient of hazard autoregression $C_{N}$ (7). It shows the proportion between the observed number of tremors $N_{f}^{*}$ recorded within the prediction time window, and the expected number of seismic events $N^{*}{ }_{\Delta t}$ of a given energy predicted from Gutenberg-Richter distribution using Eq. (5) for that time interval $\Delta T$.

$\frac{N_{f}^{*}}{N_{\Delta t}^{*}}=C_{N}$

The interpretation of the coefficient of hazard autoregression $C_{N}$ is as follows:

- $C_{N}$ value smaller than 1 means a greater predicted than observed number of tremors (more conservative prediction),

- $C_{N}$ value is 1 -perfect prediction,

- $C_{N}$ value greater than 1 means a greater number of observed than predicted tremors.

Greater number and energy of predicted tremors compared to observed numbers is more favourable in mining 
engineering, because, in this case, rockburst hazard procedures for staff are implemented before the mining field (or a part of this field) extraction starts. Of course, if prophylactic means are overestimated, they can restrain the mining work advance considerably, what is not proved by observed seismic level hazard. The reliability of prognosis decreases so the key question then is what can be the acceptable error of a prognosis. In mining practice, it is chosen with regard to experience, a mining system and possible consequences in the mining field.

The probability $Z_{\Delta t}^{s}$ of occurrence of prognosed tremors higher than $10^{4} \mathrm{~J}$ for the chosen time window $\Delta T$ was also determined (acc. to Eq. 6) during the analysis.

\section{Mining and geological conditions, and seismicity distribution}

The analysis was conducted for the IIa-S longwall face in seam 501 of Murcki-Staszic coal mine. The longwall face is placed at a depth of 923-946 m. The coal bed in this region is irregularly shaped, and its thickness ranges between 3.7 and $7.25 \mathrm{~m}$, with an average of $6.5 \mathrm{~m}$.

The maximum thickness of Quaternary and Neogene cover is $10 \mathrm{~m}$ only. Coal-bearing Carboniferous rocks occur beneath the cover, consisting of alternating layers of claystone, mudstone, sandstone and coal. There is a thick bed of sandstone in the roof of the seam 510. Its uniaxial compressive strength is about $60-75 \mathrm{MPa}$. This is the main source of seismic events in the analysed mining area. Alternating layers of claystone and sandstone of a total thickness 20-35 m are deposited under seam 510.

Longwall IIa-S was mined for 288 days from 23 September 2015 until 16 July 2016.

The seismic database collected at the "Murcki-Staszic" mine contained 4264 records including tremor date, time, coordinates and energy, of which 31 were for longwall Ia-S,

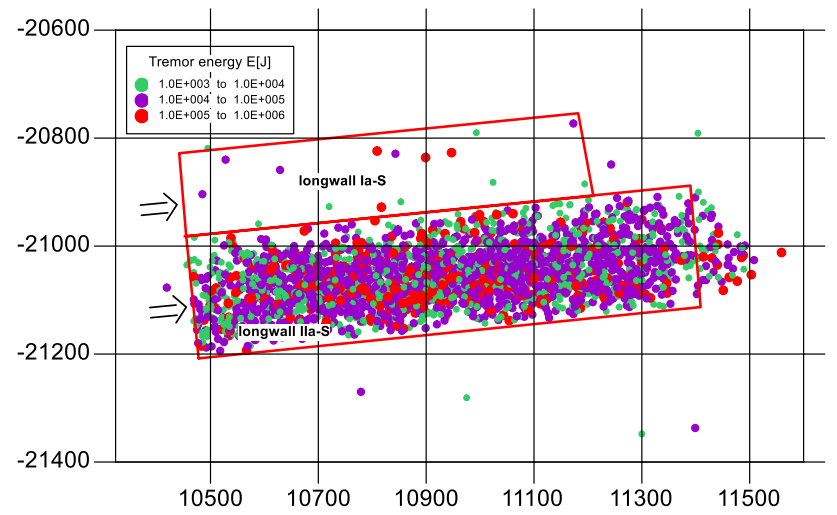

Fig. 1 The location of the recorded tremors in the areas of longwalls Ia-S and IIa-S of "Murcki-Staszic" coal mine and 4233 for longwall IIa-S (Fig. 1). This means that it was only after the mining of the second longwall that seismic events in the rock mass intensified and were numerous enough for analysis.

The record of just 31 events occurring over 7 months of mining the first longwall is too small for any statistical analysis. Low seismic activity in the rock mass at the beginning of mining operations in a given region is typical for longwall mining, as with initially small area of goaves the roof remains undisturbed. Only when a considerable opening of a mining field is formed, the dynamic breakage of strata occurs. The time of appearance, and intensity of seismic events depend on stiffness of the rock layers which are able to concentrate the elastic energy. It is noteworthy that the seismic activity continued for a period of 41 days after the extraction of the mining field with longwalls Ia-S and IIa-S had ended.

It is also remarkable that some of the tremors occurred in front of the mining face, also beyond the mining panel. Therefore, in case of seismic hazard analysis for longwall mining, the assumption appears incorrect for Gutenberg-Richter analysis that tremors only from within the region of mining panel extraction should be analysed. In this case, the assessment and prediction of seismic hazard should include the seismic database of events located eastward from the analysed longwall parcels, in order not to omit of any group of tremors caused by mining activity. These tremors may change the results of analysis, especially for higher energies events.

\section{Estimation of the optimal time window for seismic hazard prediction}

\section{Assumptions for analysis}

The analysis was performed generally for two setups:

1. Base periods from 10 to 90 days, with a step of 5 days, and the same number of days in corresponding prediction time windows,

2. Shorter prediction time windows than base periods. Considering 288 days of longwall mining, the selected base periods were 90, 50, 30 and 10 days, and the corresponding prediction time windows were 2 to 9 times shorter.

In the analysis of the first setup, distributions of parameter $b$ were compared to the number of tremors and their energies in order to check whether parameter $b$ correctly responds to the increase or decrease in seismic activity. It was assumed in the analysis that the minimum correctly observed energy in the obtained seismic database was $E_{p}=1 \times 10^{2} \mathrm{~J}$. 
In the analysis of the second setup, the selected 90, 50, 30 and 10-day base periods were obtained by dividing the total mining time into three 90-day periods, six 50-day periods, nine 30-day periods and twenty-eight 10-day periods.

A $\log N_{T}(E)=\mathrm{f}(\log E)$ graph was prepared for the database, and the probability of the occurrence of a tremor of a given energy was calculated for a prediction at the confidence level of 0.05. In the next step, histograms of the coefficient of hazard autoregression were introduced that show the effectiveness of seismic hazard predictions for selected time window.

It should be emphasised that the coal extraction was carried out only on weekdays, which means that every 5 days there was a weekend break in the advance of the longwall face. The stoppage of longwall panel advance for weekends always results in an increase in elastic energy concentration in the rock mass (an abutment pressure) next to the front of longwall face.

\section{Analysis of time windows equal to base periods}

For the analysis of the setup 1, in which base periods and prediction time windows were equal and were set from 10 to 90 days, with a step of 5 days, two assumptions were made:

- For every base period $T(T=10,20,30, \ldots, 90$ days), the prediction time window $\Delta t$ is equal to $T$,

- The prediction covered the period in which longwall panel was still mining.

Figure 2 presents the results of analysis for selected prediction periods.

An analysis of the charts above shows that base periods 10 and 20 days are too short to obtain a sufficient seismic database for the calculation of coefficient $b$ (Fig. 2a, b) in analysed geological and mining conditions. As for longer prediction periods of 70-90 days, they result in a gradual reduction in the value of coefficient $b$, the number of tremors and their seismic energy, which leads to smaller differences between the consecutive periods (Fig. $2 \mathrm{~g}-\mathrm{i}$ ). It is apparent that the most effective prediction can be achieved using a 30- or 40-day prediction time window (Fig. 2c, d).

In this option, in the conditions of the longwall IIa-S it was possible to determine coefficient $b$ for all base periods. The total amount of energy induced in the rock mass and the number of seismic events significantly differed in the analysed base periods.

It is also worth to note, that in a period directly after the start of the mining of longwall IIa-S, the value of the calculated coefficient $b$ remains virtually unchanged. Therefore, it can be concluded, that the small number of seismic events, recorded in the early stage of mining, does not allow for appropriate determination of coefficient $b$. Once the opening formed in the mining field, which, in the analysed case, was in total about $300 \mathrm{~m}$, is large enough to cause a significant seismic activity in the rock mass, the seismic database becomes sufficient for the analysis.

\section{Analysis of prediction effectiveness in time windows shorter than base periods}

\section{0-day base period}

For the analysis, the whole database was divided into three 90-day base periods starting from the first recorded tremor induced by mining. The analysis of tremor probability based on the division of the records into only 3 base periods shows that this number of base periods is insufficient to perform a correct assessment of the hazard level (Table 1).

The seismic records, hence, the database, cover the whole period of mining including the initial stage when the events of energies higher than $1 \times 10^{6} \mathrm{~J}$ are rare, and the later stage when the probability of occurrence of increase to about $55 \%$. Therefore, if the study is based on seismic activity from the initial period of mining, the higher-energy seismic occurrences are underestimated.

Only two predictions were performed: prediction for the second 90-day time window based on the records in the first 90-day period, and for the third 90-day time window based on the records in the second 90-day base period of longwall IIa-S mining.

Figure 3 shows that predictions of seismic hazard for period 2, which are based on the seismicity from the first 90-day base period, i.e. the initial stage of mining, are inconsistent. However, the predictions for period 3 based on base period 2 show the dependency graph almost linear.

This means that after the development of rock mass seismicity at the vicinity of the longwall panel an accurate prediction of seismic hazard was obtained using the Gutenberg-Richter distribution. The graph indicates an increase in accuracy of predictions of seismic hazard obtained from Gutenberg-Richter equation together with an increase in seismicity in longwall area- $C_{N}$ coefficient value is close to 1 for the third period. The seismicity increase, together with the longwall progress, causes also an apparent rising tendency of the ratio of observed to predicted tremors.

The value of coefficient of autoregression close to 1 was generally obtained for 60-day time window of prognosis for both periods 2 and 3. For time windows shorter than 60 days, the seismic hazard prognosis is largely overestimated for the 2nd period. Hence, the analysis shows that seismic hazard prediction effectiveness for 90-day database is poor, because the correct prediction can be used only for 3rd 90-day period of longwall panel extraction. 
Fig. 2 The charts of total seismic energy and GutenbergRichter coefficient $\mathrm{b}$ for: $\mathbf{a}$

10-day period, b 20-day period, c 30-day period, d 40-day period, e 50-day period, $\mathbf{f}$ 60-day period, $\mathbf{g} 70$ - day period, h 80-day period, and 90-day period
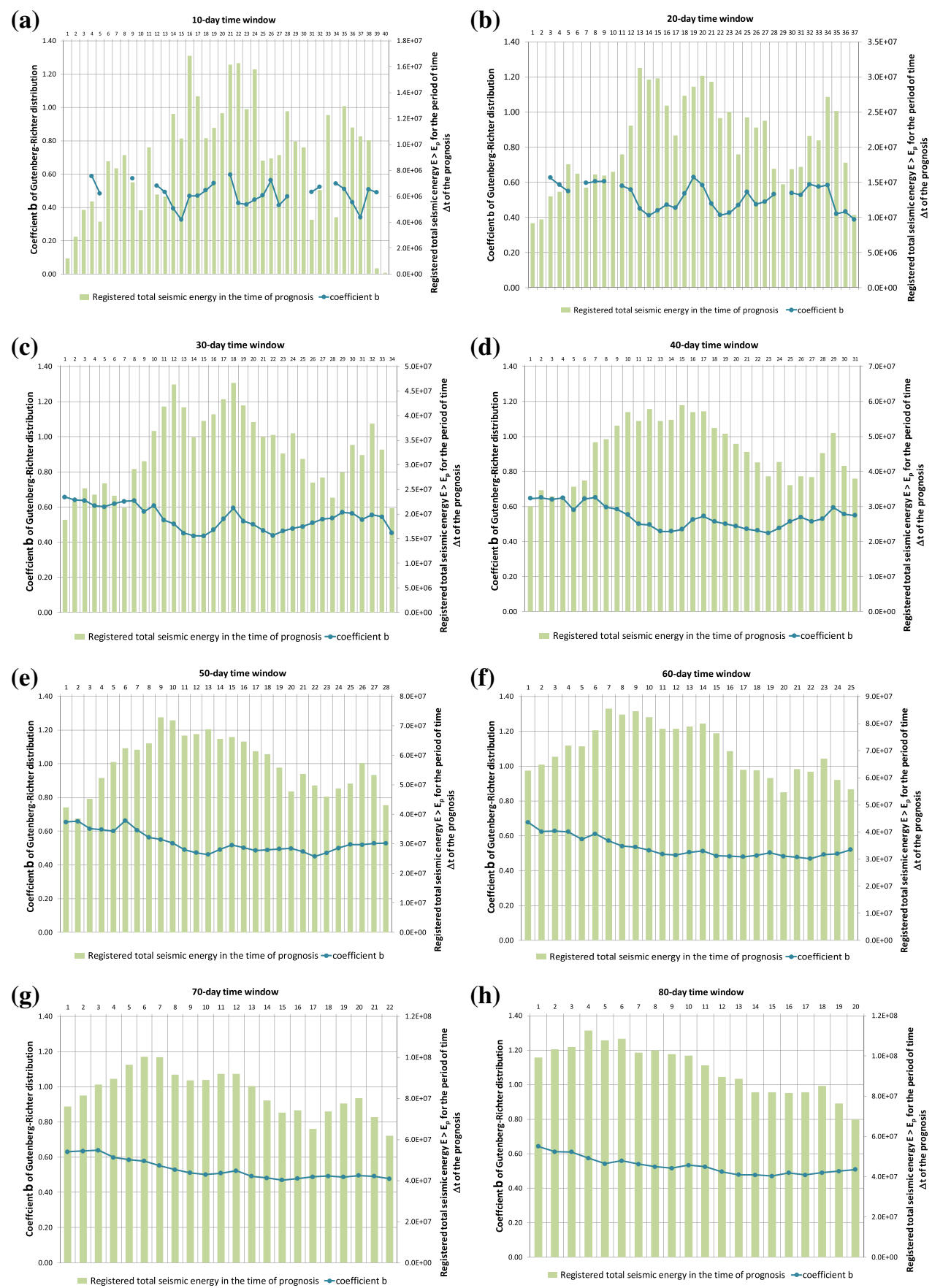

(h)

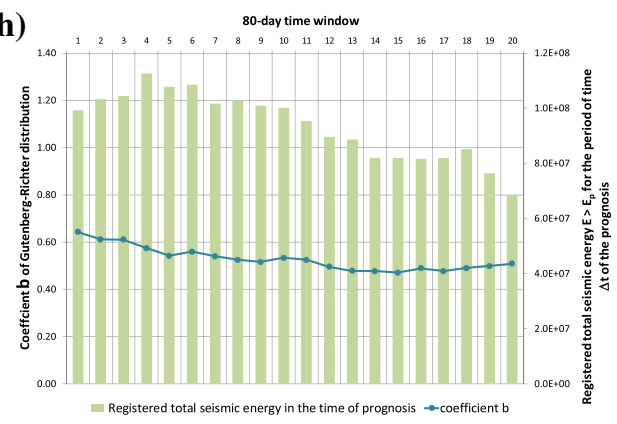

(i)

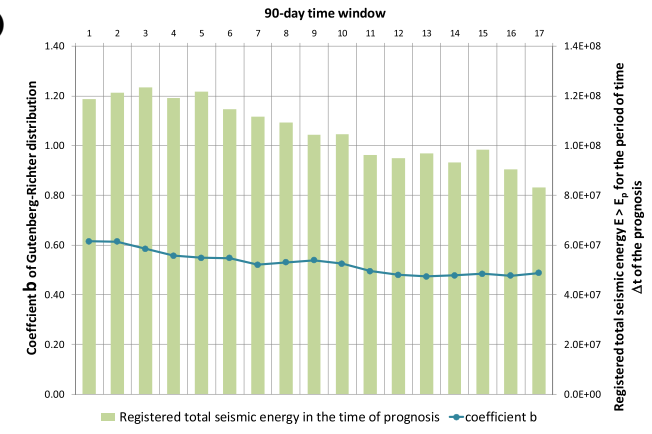


Table 1 Prediction probability of the tremor occurrence of the given energy for 90 -day base period

\begin{tabular}{lll}
\hline Energy & $\begin{array}{l}\text { Probability in base period } \\
2(\%)\end{array}$ & $\begin{array}{l}\text { Probability in } \\
\text { base period 3 } \\
(\%)\end{array}$ \\
\hline E04 & 100.0 & 100.0 \\
E05 & 100.0 & 100.0 \\
E06 & 27.6 & 54.7 \\
\hline
\end{tabular}

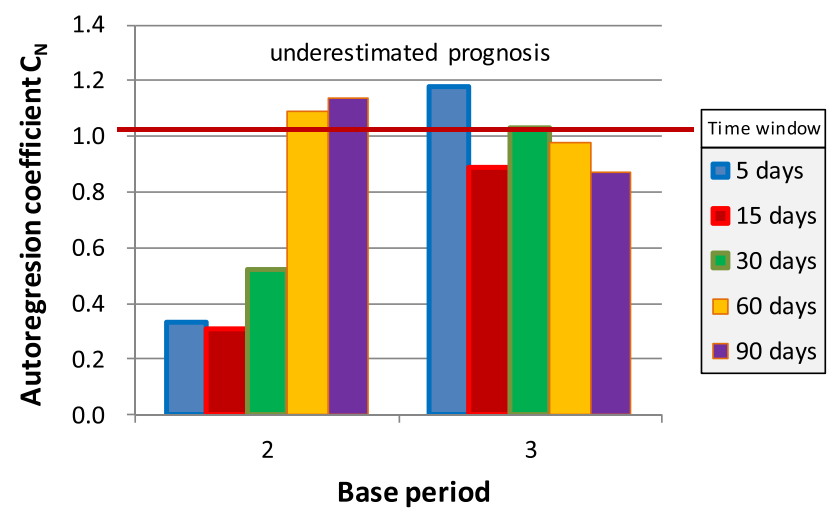

Fig. 3 Diagram of the coefficient of autoregression for consecutive periods if $T=90$ days exceedances occurring only for the full 50-day prediction period. For prediction periods 4 and 5, i.e. during mining a central section of the longwall IIa-S panel, the effectiveness of assessment of seismic hazard appeared to be very high. The full 50-day time window seems to be most adequate period to achieve reliable seismic hazard prognosis. Panel IIa-S has been extracted for 288 days, so the 6th period considers fewer number of days in the base period and it does not allow for reasonable assessment of seismic hazard.

\section{0-day base period}

Assuming 30-day period, nine such periods were distinguished. Comparing the estimated probability of seismic events for 30-day period to those for 90- and 50-day periods, it can be noted that there is a slightly smaller probability of occurrence of events of energies of $10^{5}-10^{6} \mathrm{~J}$ (Table 3). For events of energies $10^{6} \mathrm{~J}$, the probability ranges between 6 and $47 \%$, and it is very variable for the first periods of longwall panel advance.

Figure 5 presents changes of the coefficient of autoregression. It appears that base period 5 was the riskiest in the context of the prediction, considering the recorded data. For this base period, the number of observed tremors was
Table 2 Prediction probability of the tremor occurrence of the given energy for 50-day base period

\begin{tabular}{lccccc}
\hline Energy & Period 2 $(\%)$ & Period 3 $(\%)$ & Period 4 $(\%)$ & Period 5 $(\%)$ & Period 6 $(\%)$ \\
\hline E04 & 100.00 & 100.00 & 100.00 & 100.00 & 100.00 \\
E05 & 99.11 & 99.63 & 99.93 & 99.99 & 99.93 \\
E06 & 18.95 & 16.77 & 26.07 & 40.87 & 36.62 \\
\hline
\end{tabular}

\section{0-day base period}

Assuming 50-day period six such long periods were distinguished. Analysis of the values of probabilities of seismic events within these 6 periods shows they are generally smaller in comparison with 90-day periods (Table 2).

Events of energies of a range of $10^{5} \mathrm{~J}$ are never predicted with $100 \%$ probability. The probability of events with energies of $10^{6} \mathrm{~J}$ consistently increases from a dozen or so percent to up to $41 \%$ in last two prediction time periods.

Figure 4 presents aggregated changes of the autocorrelation coefficient. It clearly indicates that the most risky in the context of the seismic hazard prediction is period 2, i.e. the first predicted period, where the coefficient of autocorrelation $C_{N}$ is 2 for the time window 5 and 10 days and 1.5 for the time window 50 days. It means that the number of tremors is twice underrated for shorter prediction periods and about 1.5 times underrated for the full observation range of 50 days. For period 3, there is a visible increasing tendency of the ratio of observed to predicted tremors, with

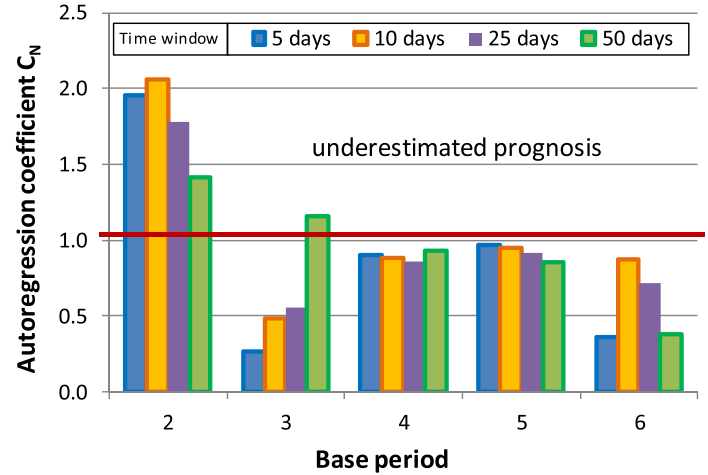

Fig. 4 The coefficient of autoregression for consecutive periods if $T=50$ days

more than double of the number of tremors predicted with the use of Eq. 5. Unexpectedly, similar conclusion comes from base period 3, where the observed number of tremors is 
Table 3 Prediction probability of the tremor occurrence of the given energy for 30-day base period

\begin{tabular}{lcccccccc}
\hline Energy & Period 2 $(\%)$ & Period 3 $(\%)$ & Period 4 $(\%)$ & Period 5 $(\%)$ & Period 6 $(\%)$ & Period 7 (\%) & Period 8 (\%) & Period 9 (\%) \\
\hline E04 & 100.00 & 100.00 & 100.00 & 100.00 & 100.00 & 100.00 & 100.00 & 100.00 \\
E05 & 98.22 & 95.43 & 93.10 & 99.51 & 99.70 & 99.58 & 99.36 & 98.69 \\
E06 & 47.50 & 9.04 & 5.59 & 15.85 & 30.09 & 23.55 & 24.91 & 22.72 \\
\hline
\end{tabular}

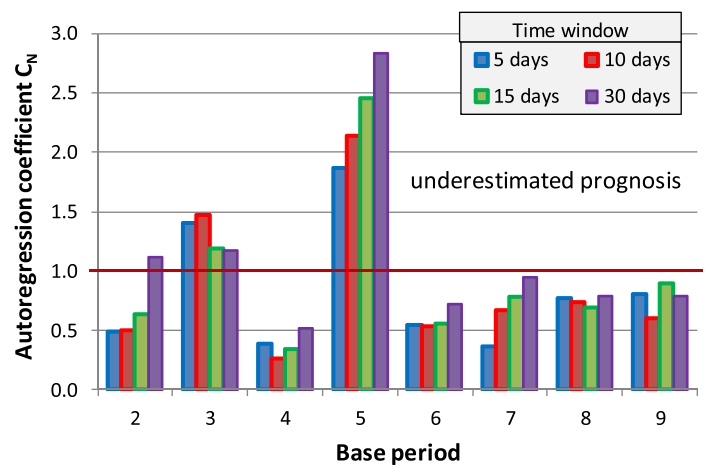

Fig. 5 The coefficient of autoregression for consecutive periods if $T=30$ days

about 1.5 times the predicted number. In the remaining base periods, the number of predicted tremors is overestimated, sometimes even twofold. It is worth noting that the time windows shorter than 30 days cause principally lower values of coefficient of autocorrelation and less effective assessment of seismic hazard.

\section{0-day base period}

Assuming 10-days periods, 28 such periods were distinguished. It is observable in Fig. 6, that the 10-day base period is too short to observe a representative number of high-energy mining-induced tremors. In this case, the seismic database is too small to allow for the correct application of the Gutenberg-Richter distribution, and the determination of parameter $b$, except only for low seismic energies. This in turn, precludes correct prediction of rockburst hazard. The seismic database of the recorded tremors enables the estimation of the probability of further seismic events.

The probabilities obtained in case of 10-day base period are lower (Table 4) than the ones in other base periods. The probability of occurrences of energy of $10^{6} \mathrm{~J}$ are calculated as low as several or a dozen or so percent, while the probability of occurrences of energies of $10^{5} \mathrm{~J}$ varies from 77 to $90 \%$. In addition, the fact that high-energy tremors are not recorded in the initial base periods prevents the determination of the probability of occurrences of energies of $10^{6} \mathrm{~J}$ in 9 periods, and occurrences of energies of $10^{5} \mathrm{~J}$ in 2 periods.

From 10-day measurement data bases, additional predictions were made for 2- and 5-day time windows.
Fig. 6 Diagram of the coefficient of autoregression for consecutive periods if $T=10$ days

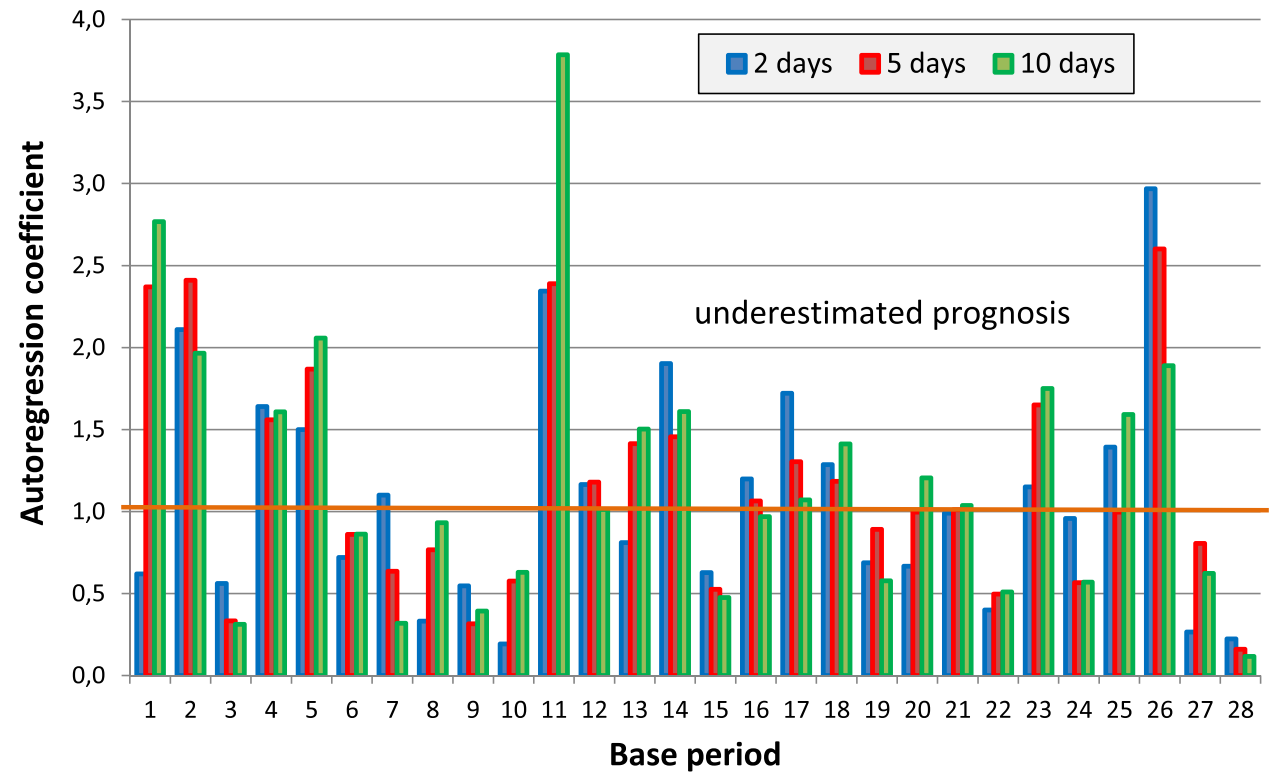


Table 4 Prediction probability of the tremor occurrence of the given energy for 10-day base period

\begin{tabular}{|c|c|c|c|}
\hline Energy & E04 (\%) & E05 & E06 \\
\hline For period 2 & 99.96 & - & - \\
\hline For period 3 & 100.00 & - & - \\
\hline For period 4 & 100.00 & $79.79 \%$ & $18.71 \%$ \\
\hline For period 5 & 100.00 & $95.55 \%$ & - \\
\hline For period 6 & 100.00 & $95.61 \%$ & - \\
\hline For period 7 & 100.00 & $88.86 \%$ & - \\
\hline For period 8 & 100.00 & $72.81 \%$ & $4.81 \%$ \\
\hline For period 9 & 100.00 & $89.72 \%$ & - \\
\hline For period 10 & 100.00 & $80.04 \%$ & $5.59 \%$ \\
\hline For period 11 & 100.00 & $90.87 \%$ & $6.67 \%$ \\
\hline For period 12 & 100.00 & $87.65 \%$ & $8.27 \%$ \\
\hline For period 13 & 100.00 & $77.66 \%$ & $3.39 \%$ \\
\hline For period 14 & 100.00 & $75.30 \%$ & $5.31 \%$ \\
\hline For period 15 & 100.00 & $74.12 \%$ & $6.27 \%$ \\
\hline For period 16 & 100.00 & $70.91 \%$ & $6.27 \%$ \\
\hline For period 17 & 100.00 & $94.91 \%$ & $18.71 \%$ \\
\hline For period 18 & 100.00 & $86.81 \%$ & $9.84 \%$ \\
\hline For period 19 & 100.00 & $84.45 \%$ & $9.39 \%$ \\
\hline For period 20 & 100.00 & $79.30 \%$ & $8.27 \%$ \\
\hline For period 21 & 100.00 & $87.31 \%$ & $12.90 \%$ \\
\hline For period 22 & 100.00 & $90.29 \%$ & - \\
\hline For period 23 & 100.00 & $86.16 \%$ & $17.16 \%$ \\
\hline For period 24 & 100.00 & $86.94 \%$ & - \\
\hline For period 25 & 100.00 & $76.99 \%$ & $8.27 \%$ \\
\hline For period 26 & 100.00 & $83.45 \%$ & - \\
\hline For period 27 & 100.00 & $97.95 \%$ & $24.13 \%$ \\
\hline For period 28 & 100.00 & $87.65 \%$ & $9.84 \%$ \\
\hline
\end{tabular}

Autoregression coefficient $C_{N}$ values (Fig. 6) demonstrate that the predictions are highly varied across all time windows, what proved that 10-day database was too short for this analysis. The predicted number of tremors for half of the base periods (time window $=5$ days) is underestimated. For base period 11th even 3.8 times for a 10-day time window (about 2.4 times for shorter time windows) and for base period 26th-about 3 times for a 2-day time window. In contrast, for 3rd base period the number of predicted tremors was at least 2 times higher than the number of the observed tremors.

\section{Conclusions}

The possibility of assessing the seismic hazard on the basis of observed seismic events for longwall mining is limited. If there are no tectonic disturbances next to the mining panel, such events usually occur alongside significant roof opening over the mining field as a result of an extraction of large volume of rock, as emphasised by Srinivasan et al. (1997).

In the presented longwall panel, intensive seismic events appeared only after an excavated length of ca. $300 \mathrm{~m}$ was achieved. It is important to note that the subject of the analysis was the second longwall panel extracted in the mining field, so the rock mass was already disturbed by mining activity. Nevertheless, the Gutenberg-Richter distribution could be applied, yet under certain conditions. The Gutenberg-Richter model is ineffective due to small number of tremors in the initial stage of the longwall mining. The reliability of seismic hazard predictions increases in the next stages, together with growing area of the excavated panel and growing number of observed tremors.

The 10- and 20-day base periods of observed tremors are too short for seismic hazard prediction purpose. In many cases, higher-energy seismic events do not occur within such a short period of time, precluding regression analysis and parameter $b$ determination, which confirms the conclusions by Kulhanek (2005) and Lasocki (2008): the shorter base periods, the smaller probability of predicted number of highenergy tremors.

The informative time window for the seismic hazard prognosis seems to be 30-50 days in the analysed geological and mining conditions. Seismic database from 30 to 90 days of observations appeared to be of a sufficient size to carry out the seismic hazard analysis with the help of Gutenberg-Richter model. Ninety-day base period database allows for a reliable hazard prognosis in 30-50-day time window for the prognosis. Whereas, from 30-day database the prediction time window rather should not be longer than 30 days.

Low energies of tremors, and infrequent high-energy events, cause the probability of prediction of seismic mining events of energy min. $1 \times 10^{6} \mathrm{~J}$, as low as $10-40 \%$, even for longer database periods. There are known methods that provide good results despite incomplete and uncertain data (Kijko and Funk 1994; Wesseloo 2018).

It is worth noting that weak tremors in many cases are not registered because their source is too far from the seismometer and the wave field is completely attenuated in the rock mass. It also happens in case of stronger tremors too. This, in turn, affects the interpretation of the Gutenberg-Richter distribution in terms of the incomplete number of tremors and their energies. This situation is characteristic of longwall coal mining.

The presented analysis confirms that Gutenberg-Richter distribution should serve rather as a complementary method used alongside, e.g. probabilistic seismic hazard analysis. 


\section{Compliance with ethical standards}

Conflict of interest On behalf of all authors, the corresponding author states that there is no conflict of interest.

Open Access This article is licensed under a Creative Commons Attribution 4.0 International License, which permits use, sharing, adaptation, distribution and reproduction in any medium or format, as long as you give appropriate credit to the original author(s) and the source, provide a link to the Creative Commons licence, and indicate if changes were made. The images or other third party material in this article are included in the article's Creative Commons licence, unless indicated otherwise in a credit line to the material. If material is not included in the article's Creative Commons licence and your intended use is not permitted by statutory regulation or exceeds the permitted use, you will need to obtain permission directly from the copyright holder. To view a copy of this licence, visit http://creativecommons.org/licenses/by/4.0/.

\section{References}

Bishop I, Styles P, Allen M (1993) Mining-induced seismicity in the Nottinghamshire Coalfield. Q J Eng Geol 26:253-279

Gibowicz SJ, Kijko A (1994) An introduction to mining seismology. Academic Press, New York

Gołda I, Kornowski J (2011) Zastosowanie rozkładu Gutenberga-Richtera do prognozy zagrożenia sejsmicznego, wraz z oceną jego niepewności (Applying the Gutenberg-Richter distribution to predict seismic hazard, along with uncertainty assessment). Gornictwo i Geologia (Min Geol) 6(3):49-62 ((in Polish))

Gutenberg B, Richter CF (1954) Seismicity of earth and associated phenomenon, 2nd edn. Princeton Univ. Press, Princeton

Kijko A, Funk CW (1994) Assessment of seismic hazard in mining. J South Afr Inst Min Metall 6:179-185

Kornowski J, Kurzeja J (2012) Prediction of rockburst probability given seismic energy and factors defined by the expert method of hazard evaluation (MRG). Acta Geophys 60(2):472-486

Kołodziejczyk P, Kornowski J, Gołda I (2013) Zagrożenie sejsmiczne od wstrząsów górniczych w warunkach niepewnej informacji (Mine-induced seismic hazard under conditions of uncertain information). Górnictwo i Geologia (Min Geol) 8(2):47-60 ((in Polish))

Kulhanek O (2005) Seminar on b-value. Dept. of Geophysics, Charles University, Prague, 10-19 Dec 2005.

Kurzeja J, Kornowski J (2013) The basic assumptions of the quantitative version of the comprehensive method of rockburst hazard evaluation. Min Resour Manag 29(2):193-204. https://doi. org/10.2478/gospo-2013-0012

Lasocki S, Orlecka-Sikora B (2008) Seismic hazard assessment under complex source size distribution of mining-induced seismicity. Tectonophysics 456:28-37

Lasocki S (2008) Some unique statistical properties of the seismic process in mines. In: Southern hemisphere international rock mechanics symposium, SHIRMS, 16-18 Sept 2008, Perth, Western Australia, Australian Centre for Geomechanics (Potvin, Carter, Dyskin \& Jeffrey eds.), Perth, Western Australia, pp 667-678

Lu C-P, Liu G-J, Liu Y, Zhang N, Xue J-H, Zhang L (2015) Microseismic multi-parameter characteristics of rockburst hazard induced by hard roof fall and high stress concentration. Int J R Mech Min Sci 76:18-32

Mendecki A, Lötter E (2018) Modelling seismic hazard for mines. In: Proceedings of: Australian Earthquake Engineering Society, 18-20 November 2011 Barossa Valley, South Australia. https:// www.researchgate.net/publication/236183155_Modelling_Seism ic_Hazard_for_Mines. Accessed 09 July 2018.

Srinivasan C, Aroras SK, Yaj RK (1997) Use of mining and seismological parameters as premonitors of rockbursts. Int J Rock Mech Min Sci 34(6):1001-1008

The complex exploitation design of coal seams prone to rockburst hazard in KHW „Murcki-Staszic” hard coal mine for $2014 \div 2017$. KHW, Katowice, Murcki-Staszic" hard coal mine; 2014 - unpublished (in Polish)

Van Aswegen G (2001) Evaluation of the risk to underground mine personnel due to the rockmass response to continuous mining operations. Report. Sandton: Safety in Mines Research Advisory Committee, ISS International Limited

Wesseloo J (2014) Evaluation of the spatial variation of $b$ value. J South Afr Inst Min Metal 114:823-828

Wesseloo J (2018) The spatial assessment of the current seismic hazard state for hard rock underground mines. Rock Mech Rock Eng 51:1839-1862. https://doi.org/10.1007/s00603-018-1430-4 